\title{
Presentación
}

La gestión de recursos humanos en las organizaciones públicas es una de las áreas en la que se centran las reformas que, a lo largo de las dos últimas décadas, han comenzado a transformar el sector público de numerosos países. Ello explica que el Consejo de Redacción de GAPP haya querido dedicar a este tema este segundo número de la revista, de cuya coordinación editorial me he hecho cargo, a petición de su director.

En nuestro país, el acuerdo Administración-Sindicatos de septiembre de 1994 ha supuesto en cierta forma el pistoletazo de salida de un debate sobre el empleo público, en torno al cual giran, desde diferentes perspectivas, los contenidos del primer bloque de la revista, bajo el enunciado Crisis y renovación del empleo público.

A la reflexión sobre el significado y alcance de este debate he dedicado el artículo con el que se abre este bloque, que se orienta a poner de manifiesto tanto el potencial cuanto los limites de la reforma legal anunciada. En el artículo se mantiene la necesidad de estrategias de cambio que vayan más allá de los marcos jurídicos, y se defiende a la vez una reforma legal capaz de enfrentar rasgos profundos de nuestro modelo de empleo público, cuya persistencia dificulta la adaptación de las organizaciones públicas al entorno y sus exigencias.

El instrumento planes de empleo centra la reflexión de Alberto Palomar, desde una concepción integrada de la planificación de personal que, trascendiendo la visión meramente cuantitativa o dotacional, la convierte en un eje central de la gestión de recursos humanos.

El artículo de Jon Azúa une al interés intrínseco de su aportación, focalizada en el análisis dinámico del entorno del empleo público, el hecho de tratarse de la infrecuente reflexión de un político de primer nivel, con una rica y dilatada experiencia de gobierno, sobre empeños reformadores que precisan de amplias dosis de visión y liderazgo.

El papel de los sindicatos en el proceso de modernización de nuestro sistema público, a lo largo de la última década, es abordado por Juan Lobato en un artículo que sitúa la reflexión en el plano de los actores del cambio. El autor propone una visión personal, que no rehuye la polémica, acerca del juego de influencias e intereses que gravitan sobre las reformas, postulando una mayor implicación de las centrales sindicales en el cambio estratégico.

Esta primera sección incluye el análisis de las reformas del empleo público en dos países que pueden ser considerados referentes valiosos para su contrastación con nuestra realidad. En el primero de ellos, Manuel Martínez Bargueño disecciona la reforma del empleo público en Italia, caracterizada por un proceso evolutivo tendente a la convergencia con el empleo privado, lo cual dota a este trabajo de un singular interés para nosotros.

La crisis del Estado de Bienestar, en el país que durante décadas ha sido su escenario paradigmático, es el entorno en el que Lennart Gustafsson sitúa las reformas de la Administración en Suecia. En ese contex- 
to, las innovaciones de la gestión de recursos humanos juegan un papel central. Una especial importancia adquiere, en la experiencia sueca de reforma, la participación del personal a través de las organizaciones sindicales, que incorpora fórmulas novedosas, descritas en el artículo.

La sección Experiencias y Casos incluye tres supuestos de innovación directamente descritos por sus protagonistas, cuyo indudable interés radica sobre todo en que se proponen enfrentar algunas de las carencias centrales de la gestión pública en nuestro mundo administrativo.

El artículo de Carlos Losada y Joan Xirau describe las bases conceptuales y metodológicas del plan de evaluación de recursos humanos de la Generalitat de Cataluña. Se trata de un proyecto orientado a la evaluación del desempeño individual, en el marco de estrategias de potenciación del papel directivo de los cuadros de la Administración, y con objetivos centrados en el cambio cultural y el aprendizaje organizativo.

Por su parte, Jaime Bouzada resume en su trabajo la orientación seguida en este campo por la Xunta de Galicia, en el marco más amplio del papel de la Inspección General de Servicios en dicha Administración. Encontramos aquí un propósito orientado a la medición del rendimiento de unidades organizativas, desde la convicción de que ello facilita una mejor valoración global del trabajo colectivo.

Por último, se incluye la experiencia de CEMICAL, que se relaciona con la búsqueda de mecanismos de resolución de conflictos en el ámbito del empleo público. Joan Mauri describe esta iniciativa de base consorcial, desarrollada para la función pública local en el marco de la provincia de Barcelona, cuyo carácter rigurosamente innovador la hace merecedora de atención ante los déficit notables del sistema de gestión pública de recursos humanos.

En resumen, creo que el lector interesado en los problemas del empleo público, y en general en el debate de las políticas públicas de recursos humanos, hallará en este número 2 un conjunto plural de aproximaciones teórico-prácticas que contribuya a alimentar el debate de reflexiones y perspectivas capaces de enriquecerlo y, sobre todo, de estimularlo.

\section{Francisco Longo}

El resto de este segundo número de GAPP se compone de las habituales secciones de Informes sobre procesos de cambio en otros países, y de América Latina. En el primer caso contamos con un excelente artículo del conocido politólogo italiano Bruno Dente, quien analiza la experiencia italiana de forma crítica, extrayendo conclusiones que trascienden las vicisitudes del país trasalpino. El artículo de Ernesto Cohen y Rolando Franco, expertos de la CEPAL de Santiago de Chile, aborda un problema de la máxima actualidad en plena efervescencia del “ $0,7 n$ : ¿cuál es la efectividad real de los programas de ayuda al desarrollo en aquella región y cómo puede mejorarse ese rendimiento atendiendo los aspectos cruciales de la gestión?

Incorporamos una nueva sección a este número de GAPP, mostrando así nuestra voluntad de mantener un esquema abierto y flexible de la revista para recoger aquellos aspectos de interés que puedan ir surgiendo. Hemos denominado a esta sección Repensar el Estado, y la inauguramos con un sugerente artículo de Michel Crozier, cuya personalidad no creemos exija presentación alguna. Crozier acaba de publicar un nuevo libro en Francia en el que proclama las grandes dificultades de las élites para aceptar los procesos de cambio, pero aquí nos muestra su concepción del Estado como realidad modesta (para usar la expresión de su conocido libro, "Estado Moderno, Estado Modesto") en relación a los demás poderes sociales.

Agradeciendo la gran acogida dispensada a nuestro primer número, os invitamos a hacernos llegar vuestros artículos, sugerencias y comentarios sobre una revista que queremos útil y plural.

\section{El Director}

